\title{
Techniques for blood loss estimation in major non-cardiac surgery: a systematic review and meta-analysis
}

\section{Les techniques d'estimation des pertes sanguines lors de chirurgie non cardiaque majeure : une revue systématique et méta-analyse}

\author{
Alexandre Tran, MD, MSc · Jordan Heuser, MD - Timothy Ramsay, PhD • \\ Daniel I. McIsaac, MD, MPH • Guillaume Martel, MD, MSc (1)
}

Received: 26 March 2020/Revised: 25 August 2020/Accepted: 28 August 2020/Published online: 24 November 2020

(C) Canadian Anesthesiologists' Society 2020, corrected publication 2020

\begin{abstract}
Purpose Estimated blood loss (EBL) is an important tool in clinical decision-making and surgical outcomes research. It guides perioperative transfusion practice and serves as a key predictor of short-term perioperative risks
\end{abstract}

This article was updated to correct Daniel I. McIsaac's name. It appeared incorrectly as Daniel M. McIsaac.

This article is accompanied by an editorial. Please see Can J Anesth 2021; this issue.

Electronic supplementary material The online version of this article (https://doi.org/10.1007/s12630-020-01857-4) contains supplementary material, which is available to authorized users.

A. Tran, MD, MSc $\cdot$ J. Heuser, MD

Department of Surgery, University of Ottawa, Ottawa, ON, Canada

T. Ramsay, $\mathrm{PhD}$

Ottawa Hospital Research Institute, The Ottawa Hospital General Campus, 501 Smyth Road, Ottawa, ON K1H 8L6, Canada

D. I. McIsaac, MD, MPH

Ottawa Hospital Research Institute, The Ottawa Hospital General Campus, 501 Smyth Road, Ottawa, ON K1H 8L6, Canada

Department of Anesthesiology, University of Ottawa, Ottawa, ON, Canada

G. Martel, MD, MSc ( $\square)$

Department of Surgery, University of Ottawa, Ottawa, ON, Canada

e-mail: gumartel@toh.ca

Ottawa Hospital Research Institute, The Ottawa Hospital General Campus, 501 Smyth Road, Ottawa, ON K1H 8L6, Canada and long-term oncologic outcomes. Despite its widespread clinical and research use, there is no gold standard for blood loss estimation. We sought to systematically review and compare techniques for intraoperative blood loss estimation in major non-cardiac surgery with the objective of informing clinical estimation and research standards.

Source A structured search strategy was applied to Ovid Medline, Embase, and Cochrane Library databases from inception to March 2020, to identify studies comparing methods of intraoperative blood loss in adult patients undergoing major non-cardiac surgery. We summarized agreement between groups of pairwise comparisons as visual estimation vs formula estimation, visual estimation vs other, and formula estimation vs other. For each of these comparisons, we described tendencies for higher or lower EBL values, consistency of findings, pooled mean differences, standard deviations, and confidence intervals. Principle findings We included 26 studies involving 3,297 patients in this review. We found that visual estimation is the most frequently studied technique. In addition, visual techniques tended to provide lower EBL values than formula-based estimation or other techniques, though this effect was not statistically significant in pooled analyses likely due to sample size limitations. When accounting for the contextual mean blood loss, similar case-to-case variation exists for all estimation techniques.

Conclusions We found that significant case-by-case variation exists for all methods of blood loss evaluation and that there is significant disagreement between techniques. Given the importance placed on EBL, particularly for perioperative prognostication models, clinicians should consider the universal adoption of a practical and reproducible method for blood loss evaluation. 
Trial registration PROSPERO (CRD42015029439); registered: 18 November 2015.PROSPERO (CRD42015029439); registered: 18 November 2015.

\section{Résumé}

Objectif Les pertes sanguines estimées constituent un outil important dans la prise de décision clinique et la recherche sur les pronostics chirurgicaux. Elles guident la pratique transfusionnelle périopératoire et servent de prédicteur clé des risques périopératoires à court terme ainsi que des devenirs oncologiques à long terme. Malgré l'utilisation répandue de cette modalité en clinique et en recherche, il n'existe pas de référence absolue pour l'estimation des pertes sanguines. Nous avons tenté de passer systématiquement en revue et de comparer les techniques d'estimation des pertes sanguines peropératoires dans les chirurgies non cardiaques majeures, avec pour objectif d'informer l'évaluation clinique et les normes de recherche. Source Une stratégie de recherche structurée a été appliquée aux bases de données Ovid Medline, Embase et Cochrane Library de leur création à mars 2020 afin d'identifier les études comparant les méthodes d'estimation des pertes sanguines peropératoires chez des patients adultes subissant une chirurgie non cardiaque majeure. Nous avons résumé la concordance entre des groupes de comparaisons par paires en tant qu'estimation visuelle vs estimation par formule, estimation visuelle vs autre, et estimation par formule vs autre. Pour chacune de ces comparaisons, nous avons décrit les tendances vers des valeurs d'estimations des pertes sanguines plus élevées ou plus basses, la cohérence des résultats, les différences moyennes combinées, les écarts type et les intervalles de confiance.

Constatations principales Dans ce compte rendu, 26 études portant sur 3297 patients ont été examinées. L'estimation visuelle est la technique la plus fréquemment étudiée. En outre, les techniques visuelles avaient tendance à donner des valeurs d'estimation des pertes sanguines plus basses que les estimations fondées sur des formules ou d'autres techniques, bien que cet effet n'ait pas eu de signification statistique dans les analyses combinées, probablement en raison des limites liées aux tailles d'échantillon. En tenant compte des pertes sanguines moyennes contextuelles, une variation similaire au cas par cas est apparue avec toutes les techniques d'estimation.

Conclusion Nous avons observé qu'une variation significative au cas par cas était présente avec toutes les méthodes d'évaluation des pertes sanguines et qu'il y a un désaccord significatif entre les techniques. Étant donné l'importance octroyée à l'estimation des pertes sanguines, particulièrement dans les modèles de pronostication périopératoire, les cliniciens devraient envisager l'adoption universelle d'une méthode pratique et reproductible d'évaluation des pertes sanguines.
Enregistrement de l'étude PROSPERO (CRD4201502 9439); enregistrée le : 18 novembre 2015.

Keywords blood loss $\cdot$ estimation $\cdot$ surgery

Major intraoperative hemorrhage is a foundational aspect of perioperative practice encountered daily by anesthesiologists and surgeons. Prevention and treatment of hemorrhage requires accurate and reliable measurement of intraoperative blood loss. Robust research aimed at improving patient outcomes also requires accurate methods to measure blood loss, so that surgical and anesthetic techniques can be effectively compared and volume-based physiologic consequences of blood loss can be studied. Blood loss is universally quantified within the intraoperative setting, and the estimated blood loss (EBL) value is a standard part of the intraoperative medical record. Nevertheless, methods of measuring blood loss are often complex, impractical in clinical practice, and may differ across institutions and disciplines. ${ }^{1}$

Clinical guidelines currently highlight the importance of monitoring EBL while acknowledging deficiencies in measurement techniques. In clinical practice, subjective visual quantification is most commonly utilized. ${ }^{1}$ The American Society of Anesthesiologists Task Force on Perioperative Blood Management Practice Guidelines recommends periodic visual assessments of the surgical field, suction canisters, surgical sponges, and surgical drains to assist with intraoperative blood loss monitoring. Nevertheless, the guidelines also note that the available literature is insufficient to assess the impact of EBL measurement on patient outcomes. ${ }^{2}$ Estimated blood loss is also an important component of widely used prognostic models, such as the surgical Apgar score for postoperative mortality and morbidity, ${ }^{3}$ the pancreatic fistula risk score for pancreatic fistula after a Whipple procedure, ${ }^{4}$ or the PPOSSUM score for mortality after a general surgery procedure. ${ }^{5}$ Longer-term outcomes are also predicted by EBL, including survival after colon cancer surgery ${ }^{6}$ and survival and recurrence rates after resection for hepatocellular carcinoma. ${ }^{7}$

Given the strong prognostic influence of EBL on postoperative outcomes, despite the heterogeneity and possible inaccuracy in its measurement, standard and robust methods for estimation are required to guide clinical care and research. In addition to visual estimation, ${ }^{8,9}$ other methods currently employed worldwide include formula-based estimation, incorporating changes in hemoglobin or hematocrit,,${ }^{10,11}$ and gravimetric-based estimation incorporating changes in dry and wet weight of surgical sponges, ${ }^{12,13}$ among others. 
Nevertheless, methods for comparison have not previously been systematically reviewed or adequately compared in terms of agreement and reliability. A nuanced understanding of the quantitative limitations of blood estimation techniques would allow a more representative interpretation of EBL across studies utilizing different techniques. Therefore, we conducted a systematic review and meta-analysis with the primary objective of comparing techniques of intraoperative quantitative blood loss estimation in adult patients undergoing major non-cardiac surgery. In particular, we aimed to highlight the comparison between visual estimation and lab valuebased formula estimation, focusing on differences in generated values and intrinsic variation.

\section{Methods}

This systematic review was conducted according to the Preferred Reporting Items for Systematic Reviews and Meta Analyses (PRISMA) guidelines. ${ }^{14}$ The review protocol was registered in the PROSPERO register of systematic reviews (CRD42015029439).

\section{Search strategy}

We conducted a search of the Ovid Medline, Embase, and the Cochrane Library databases from inception to 22 March 2020. A search strategy was developed under the guidance of a health research librarian from the Ottawa Hospital Library services. The search was conducted using the terms "blood loss", "blood volume", "bleeding" and "hemorrhage" with database-specific search strategies (eAppendix 1, as Electronic Supplementary Material [ESM]). Additional articles were identified from a handsearch of included references. We reviewed the clinicaltrials.gov database to assess for any in-progress or unpublished studies.

\section{Study selection}

We included all English-language full-text articles describing retrospective and prospective observational studies and randomized-controlled trials. We included studies meeting the following criteria: 1) enrolled adult patients ( $\geq 16 \mathrm{yr}$ ), 2) conducted in the operative setting for major non-cardiac procedures, 3) generated EBL volumes using two or more different techniques, and 4) evaluated either visual estimation or lab value-based formula estimation techniques in at least one of the comparison arms (Table 1). We excluded case reports, case series, animal studies, and pediatric studies. We additionally hand-searched the reference lists of all included studies to identify relevant grey literature.

Eligible surgical procedures included open, laparoscopic, or robotic procedures within neurosurgery, otolaryngology, thoracic surgery, general surgery, urology, gynecology, and orthopedic surgery. Studies involving obstetrical, endoscopic, oral, or cardiac surgeries were excluded because of negligible blood loss or intrinsic differences in underlying patient physiology (including blood volume and induced coagulopathy). Eligible techniques of blood loss estimation were limited those that generated EBL volumes-those evaluating measures of association alone, such as correlation coefficients or linear regression coefficients, were excluded. Any disagreements were resolved by consensus or by the senior author (G.M.).

We screened studies using the Covidence online screening platform (Melbourne, Australia). We imported titles into Covidence directly from the search databases and removed duplicates. Two reviewers (A.T. and J.H.) independently completed title and abstract screening followed by full-text screening. Disagreements at each stage were resolved by discussion and reaching of consensus.

\section{Data extraction}

Two investigators (A.T., J.H.) independently extracted data into a pre-defined data collection form. Publication characteristics (study title, year, author, country of origin), population characteristics (sample size, surgical discipline), and method characteristics (type of blood estimation method) were included. The primary outcome included the mean EBL of each method, as well as its coefficient of variation (CV). The primary outcome included the mean EBL of each method, as well as its measure of dispersion about the mean and CV. In addition, the mean difference in EBL between techniques was retrieved, together with measures of dispersion (standard deviation [SD], standard error, or confidence interval) or additional data to calculate the measure of dispersion. The $\mathrm{SD}$ of the mean difference was back-calculated from limits of agreement, correlation coefficients, and $P$ values for paired $t$ tests. ${ }^{15,16}$ Where $P$ values were less than 0.001 , a conservative estimate of the SD was generated by assuming the $P$ value to be 0.00099 . All $P$ values were assumed to be two-tailed unless otherwise reported by the authors. In one study reporting a $P$ value less than 0.001 from a Wilcoxon test, ${ }^{17}$ a conservative estimate of the SD was generated by assuming that the $P$ value from a comparable paired t-test would likely yield a lower $P$ value than a Wilcoxon test. As such, a $P$ value of 0.0005 was assigned to this study, as this was the lowest $P$ value that 
Table 1 Descriptions of blood loss estimation techniques

\begin{tabular}{ll}
\hline $\begin{array}{l}\text { Blood estimation } \\
\text { technique }\end{array}$ & Description \\
\hline $\begin{array}{l}\text { Visual estimation } \\
\text { Flood loss measured in suction canisters or estimated in blood-soaked sponges and drapes, most commonly determined } \\
\text { by the surgeon or anesthesiologist }\end{array}$ \\
$\begin{array}{l}\text { Calculation of blood loss based on change in calculated blood volume, determined by sex, height, weight, and change in } \\
\text { hemoglobin or hematocrit, accounting for blood transfusions and crystalloid provided } \\
\text { Calculation of blood loss based on change between dry and blood-soaked sponges, accounting for irrigation provided } \\
\text { Colorimetric }\end{array}$ \\
$\begin{array}{l}\text { Calculation of blood loss based on extracted hemoglobin weight from blood-soaked sponges and compared with known } \\
\text { preoperative hemoglobin }\end{array}$ \\
$\begin{array}{c}\text { Visual comparison of blood-soaked sponges with a standardized visual diagram of simulated blood-soaked sponges with } \\
\text { known blood loss values }\end{array}$
\end{tabular}

Table 2 Characteristics of included studies $(n=26)$

\begin{tabular}{lc}
\hline Description & $n(\%)$ \\
\hline Region of study & $9(35)$ \\
USA & $11(42)$ \\
Europe & $6(23)$ \\
Other & \\
Year of publication & $5(19)$ \\
Pre-1990s & $4(15)$ \\
1990s & $2(8)$ \\
2000s & $15(58)$ \\
2010s & \\
Study design & $19(73)$ \\
Prospective cohort & $7(27)$ \\
Retrospective cohort & \\
Discipline & $5(19)$ \\
General surgery & $2(8)$ \\
Gynecology & $10(38)$ \\
Orthopedic surgery & $4(15)$ \\
Urology & $2(8)$ \\
Other & $3(12)$ \\
Mixed disciplines &
\end{tabular}

would round up to 0.001 . Where studies did not provide calculated summary estimates of EBL or provided insufficient data to calculate these, individual data points were extracted where feasible from correlation plots comparing blood estimation methods. Estimated blood loss volumes were extracted as or converted to millilitres for each technique.

Quality assessment

Methodological quality was assessed using the Methodological Index for Non-Randomized Studies
(MINORS). ${ }^{18}$ As per the MINORS guidelines, studies were assessed for clarity of objective, eligibility criteria, data collection, study endpoints, follow-up, control group, and statistical analyses. Studies were assigned a score out of 24 possible points. All studies that met eligibility criteria were included in this review regardless of their risk of bias.

Evidence synthesis

For each study, we extracted or calculated the mean, SD, and $\mathrm{CV}$ for each blood estimation technique. The $\mathrm{CV}$ is the ratio of $\mathrm{SD} / \mathrm{mean}$ and provides a measure of relative variability (or dispersion) for a given blood loss estimation technique. Interpreting the SD as a measure of variation is done within the context of the mean. Nevertheless, the $\mathrm{CV}$ is unitless and allows for direct comparison across multiple samples with different means. ${ }^{19}$ We additionally calculated a ratio of means between the two comparison arms of each study to facilitate relative comparisons across varying effect sizes. $^{20}$ Similarly, mean differences and SD were obtained for each pair of blood estimation techniques. Mean differences, SD, and 95\% confidence intervals (CI) were pooled using the methods described by Williamson et al. for the meta-analysis of method comparison studies. ${ }^{16}$ As suggested by the authors, a random-effects model with an inverse variance method was used for meta-analysis, under the assumption of significant between-study heterogeneity. We summarized agreement between groups of pairwise comparisons as visual estimation vs formula estimation, visual estimation $v s$ other, and formula estimation $v s$ other. For each of these comparisons, we described tendencies for higher or lower EBL values, consistency of findings, pooled mean differences, SD, and limits of agreement. Funnel plots were generated to examine the possibility of publication bias. All analyses were carried out using Comprehensive Meta-Analysis version 2.2 (Englewood, NJ, USA), the R statistical package, version 4.0.2 ( $\mathrm{R}$ Core Team [2020], www.r- 
project.org), and Microsoft Excel 2010 (Redmond, WA, USA).

\section{Results}

Search results

We identified 2,002 studies. Following removal of duplicates, we screened 1,324 studies, of which 74 underwent full-text review. The PRISMA flow diagram is presented in eAppendix 2. ${ }^{14} \mathrm{We}$ included 26 studies involving 3,297 patients.

\section{Study characteristics}

Summarized study characteristics are presented in Table 2. Of the studies, nine were from North America, $8,11,17,21-26$ 11 were from Europe, ${ }^{10,12,13,27-34}$ and four were from Asia. ${ }^{9,35-37}$ Nine studies were published before $2000,{ }^{11,21,25,27,29,30,32,35,38}$ two studies were published between 2000 and $2009,,^{8,33}$ and 14 studies were published in 2010 or later. ${ }^{10,12,13,17,22-24,26,28,34,36,37,39}$ The most commonly studied operative procedures were orthopedic surgery (nine studies, 1,596 patients), ${ }^{13,23,26,28,30,33,36,37,39}$ general surgery (five studies, 687 patients), ${ }^{17,21,22,27,38}$ urology (four studies, 507 patients), $8,11,12,31$ and mixed (three studies, 336 patients). ${ }^{25,34,35}$ Individual study characteristics are presented in eAppendix 3.

\section{Quality assessment}

Risk of bias assessments were completed using the MINORS tool and are presented in eAppendix 4. Strengths of the studies represented in this review included the use of appropriate, unbiased endpoints with excellent control group standards given that blood loss evaluation allows for comparison within a single patient. Weaknesses included lack of reporting on missingness of data and sample size calculation, and variable reporting of eligibility criteria.

Results of synthesis

Summarized findings for comparisons between visual estimation $v s$ formula estimation, visual estimation $v s$ other, and formula $v s$ other are presented in Table 3. Summarized findings for intrinsic variation for each blood estimation technique are presented in Table 4.
Visual estimation vs formula estimation

We identified 12 studies $8-11,17,23,26,31-33,36,37$ involving 2,225 patients that compared visual and formula-based estimation techniques. Estimated blood loss values derived from visual techniques were lower than those derived from formula-based techniques, a finding observed in 12 of 13 $(92 \%)$ studies. Six studies $(n=974)$ provided sufficient data for meta-analysis ${ }^{8,10,11,20,23,30}$ (Fig. 1A). The pooled mean blood loss difference was $-462 \mathrm{~mL}(95 \% \mathrm{CI}$, $-1,090$ to $166 ; \mathrm{I}^{2}=99 \%$ ). Statistical heterogeneity was primarily driven by two papers, ${ }^{11,23}$ as their removal yielded a mean difference of $-303 \mathrm{~mL}(95 \% \mathrm{CI},-409$ to $\left.-197 ; \mathrm{I}^{2}=17 \%\right)$. A funnel plot is presented in eAppendix 5 . Egger's test for publication bias was not significant $(P=$ $0.480)$.

Visual estimation versus other

We identified seven studies $22,24,25,28,34,35,39$ involving 1,322 patients that compared visual and other estimation techniques. Estimated blood loss values derived from visual techniques were lower than those derived from other techniques. Five studies $(n=327)$ provided sufficient data for meta-analysis ${ }^{22,24,25,28,35}$ (Fig. 1B). The pooled mean blood loss difference was $-40.7 \mathrm{~mL}(95 \% \mathrm{CI},-136$ to $\left.55.0 ; \mathrm{I}^{2}=97 \%\right)$. Two of the pooled studies compared visual estimation with gravimetric estimation, ${ }^{28,35}$ two with colorimetric estimation, ${ }^{22,25}$ and one with pictographic estimation. ${ }^{24}$ Given the small number of pooled studies and these clear methodological differences, sensitivity analyses for statistical heterogeneity were not conducted. A funnel plot is presented in eAppendix 5. Egger's test for publication bias was not significant $(P=0.746)$.

Formula estimation versus other

We identified six studies $^{12,13,27,29,30,38}$ involving 329 patients that compared formula and other estimation techniques. In all six papers, formula estimation was compared with gravimetric estimation methods. Estimated blood loss values derived from formula-based techniques were higher than those derived from gravimetric techniques, a finding observed in all six studies. All six studies provided sufficient data for meta-analysis (Fig. 1C). The pooled mean blood loss difference was $386 \mathrm{~mL}(95 \%$ CI, 235 to $537 ; \mathrm{I}^{2}=86 \%$ ). Statistical heterogeneity was primarily driven by two papers, ${ }^{13,29}$ as their removal yielded a mean difference of $262 \mathrm{~mL}$ (95\% CI, 203 to 322; $\mathrm{I}^{2}=16 \%$ ). A funnel plot is presented in eAppendix 5 . Egger's test for publication bias was not significant $(P=$ 0.0810). 
Table 3 Agreement between blood estimation techniques

\begin{tabular}{ll}
\hline Comparison & \\
\hline Visual estimation $v s$ formula $(n=12$ studies $)$ & 2,225 \\
Sample size & Formula EBL $>$ Visual EBL \\
Directionality & $11(92 \%)$ \\
Consistency & $-462 \mathrm{~mL}\left(95 \% \mathrm{CI},-1,090\right.$ to $\left.166 ; \mathrm{I}^{2}=99 \%\right)$ \\
Pooled mean difference, main & $-303 \mathrm{~mL}\left(95 \% \mathrm{CI},-409\right.$ to $\left.-197 ; \mathrm{I}^{2}=17 \%\right)$ \\
Pooled mean difference, sensitivity & \\
Visual estimation $v s$ other $(n=7$ studies $)$ & 695 \\
Sample size & Other EBL $>$ Visual EBL \\
Directionality & $3(50 \%)$ \\
Consistency & $-41 \mathrm{~mL}\left(95 \% \mathrm{CI},-136\right.$ to $\left.55 ; \mathrm{I}^{2}=97 \%\right)$. \\
Pooled mean difference, main & \\
Formula $v s$ other $(n=6$ studies) & 329 \\
Sample size & Formula EBL $>$ Other EBL \\
Directionality & $6(100 \%)$ \\
Consistency & $386 \mathrm{~mL}\left(95 \% \mathrm{CI}, 235\right.$ to $\left.537 ; \mathrm{I}^{2}=86 \%\right)$ \\
Pooled mean difference, main & $262 \mathrm{~mL}\left(95 \% \mathrm{CI}, 203\right.$ to $\left.322 ; \mathrm{I}^{2}=16 \%\right)$ \\
Pooled mean difference, sensitivity & \\
Other $v s$ other $(n=1$ study) & 21 \\
Sample size &
\end{tabular}

Table 4 Intrinsic variation among blood estimation techniques

\begin{tabular}{ll}
\hline Technique & \\
\hline Visual ( $n=27$ cohorts) & 3,658 \\
Sample size & $0.51[0.43-0.67]$ \\
Coefficient of variation, median [IQR] & \\
Formula ( $n=10$ cohorts) & 2,581 \\
Sample size & $0.57[0.47-0.60]$ \\
Coefficient of variation, median [IQR] & \\
Other ( $n=13$ cohorts) & 1,051 \\
Sample size & $0.51[0.36-0.65]$ \\
Coefficient of variation, median [IQR]
\end{tabular}

$\mathrm{IQR}=$ interquartile range

Intrinsic variation

We used the CV to describe the dispersion of generated blood estimation values relative to the mean for each technique. The case-to-case variation was similar across all techniques with a median [interquartile range (IQR)] CV of 0.51 [0.43-0.67] for visual estimation, 0.57 [0.45-0.60] for formula-based estimation, and 0.51 [0.36-0.65] for other methods. In other words, when accounting for the mean blood loss value of a particular set of surgeries, similar variation in case-by-case EBL volumes can be expected for each technique.

\section{Discussion}

We performed a systematic review and meta-analysis to compare techniques for intraoperative quantitative blood loss estimation in adult patients undergoing major noncardiac surgery. We found that visual estimation is the most popular technique studied. In addition, visual techniques tended to provide lower EBL values than formula-based estimation or other techniques, though this effect was not statistically significant in pooled analyses, likely because of sample size limitations. When accounting for the mean blood loss value, similar case-to-case variation was noted for all estimation techniques. Taken together, our study provides important evidence for the tendencies for higher or lower EBL values as well as intrinsic variation of existing techniques for quantitative blood loss estimation during surgery. Such findings can be used to contextualize relative EBL values across studies that utilize different techniques for blood loss assessment.

Visual blood loss estimation (i.e., visual inspection of the surgical field, canisters, and sponges) was the most popular method identified in this review and typically involves a coarse interpretation of the appropriateness or excessiveness of the blood loss. Advocates of this oftenused approach note its intuitive ease and that, in the context of appropriate supporting laboratory and vital sign metrics, further granularity rarely provides additional short-term clinical insight. 
A Visual estimation vs. formula

$\begin{array}{lrrcr}\text { Study } & \begin{array}{r}\text { Mean } \\ \text { differences }\end{array} & \text { SE } & \mathbf{n} & 95 \% \mathrm{Cl} \\ \text { Bozickovic 2011 } & -612 & 252 & 14 & (-1107,-117) \\ \text { Brecher 1997 } & -1440 & 56.9 & 250 & (-1552,-1328) \\ \text { Guinn 2013 } & 246 & 35.0 & 60 & (177,315) \\ \text { McCullough 2004 } & -457 & 140 & 51 & (-732,-182) \\ \text { Orth 1998 } & -286 & 73.2 & 30 & (-429,-143) \\ \text { Sanchez 2011 } & -239 & 68.3 & 569 & (-373,-105) \\ \text { Total (95\% Cl) } & -462 & 320 & 974 & (-1090,166)\end{array}$

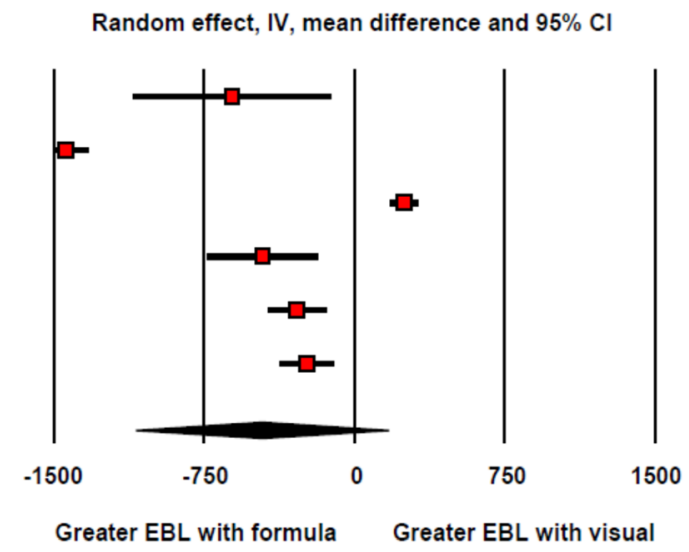

B Visual estimation vs. others

$\begin{array}{lrrrr}\text { Study } & \begin{array}{r}\text { Mean } \\ \text { difference }\end{array} & \text { SE } & \mathbf{n} & \mathbf{9 5 \%} \mathrm{Cl} \\ \text { Budair 2017 } & -175 & 38.0 & 55 & (-249,-101) \\ \text { Delilkan 1972 } & -138 & 13.8 & 100 & (-165,-111) \\ \text { Ghee 2017 } & 192 & 60.0 & 23 & (74.3,310) \\ \text { Nelson 2018 } & -93.0 & 15.5 & 81 & (-123,-62.7) \\ \text { Oppenheim 1944 } & 52.0 & 15.3 & 68 & (21.9,82.1) \\ \text { Total (95\% Cl) } & \mathbf{- 4 0 . 7} & \mathbf{4 8 . 8} & \mathbf{3 2 7} & \mathbf{( - 1 3 6 , 5 5 . 0 )}\end{array}$

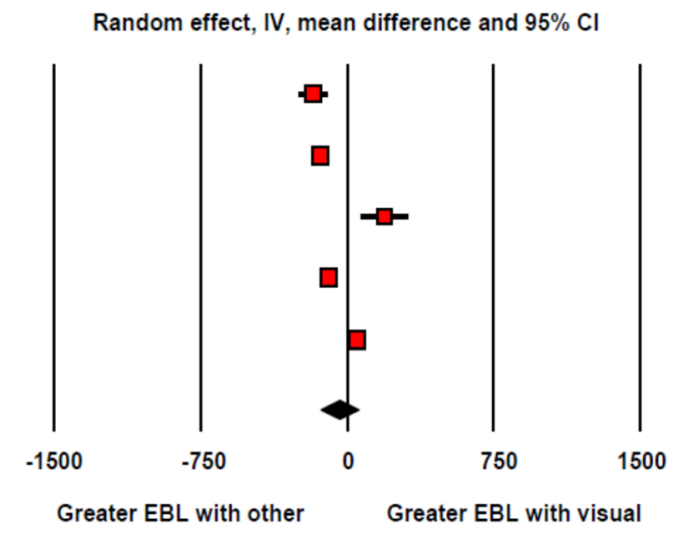

\section{Formula vs. others}

$\begin{array}{lrrcr}\text { Study } & \begin{array}{r}\text { Mean } \\ \text { difference }\end{array} & \text { SE } & \text { n } & \mathbf{9 5 \% ~ C l} \\ \text { Brockner 1969 } & 194 & 55.0 & 54 & (86.3,302) \\ \text { Budny 1993 } & 1390 & 295 & 19 & (812,1968) \\ \text { Caceres 1959 } & 342 & 63.8 & 20 & (217,467) \\ \text { Flordal 1992 } & 230 & 66.2 & 50 & (100,360) \\ \text { Jaramillo 2019 } & 283 & 43.4 & 80 & (198,368) \\ \text { Lopez-Picardo 2017 } & 634 & 79.0 & 106 & (479,789) \\ \text { Total (95\% Cl) } & \mathbf{3 8 6} & \mathbf{7 7 . 1} & \mathbf{3 2 9} & \mathbf{( 2 3 5 , 5 3 7 )}\end{array}$

Fig. 1 Meta-analysis comparing blood loss evaluation methods

The specific categorization threshold for what is deemed a meaningful level of blood loss depends upon its specific context and application. The threshold for blood loss necessitating immediate clinical action (i.e., a blood transfusion) for a single patient naturally should be different than the threshold utilized to evaluate short-term perioperative events ${ }^{5}$ or long-term cancer recurrences at a population outcomes level. ${ }^{6}$

This is why we advocate strongly for a reliable and reproducible blood loss estimation as a continuous variable 
Fig. 2 Sample blood loss calculation

Blood Loss Formula from Ross 2018:

$$
\text { PostOp Hgb }=\text { PreOp Hgb }-\left[\left(\frac{E B L}{T B V}\right) * l\right]-\left[\left(\frac{E B L}{T B V}\right) * h\right]-\left[\left(\frac{V R}{T B V}\right) * r\right]
$$

Blood loss coefficient, $I=5.111 \mathrm{~g} / \mathrm{dL}$

Estimated blood loss, EBL

Equilibration coefficient, $h=6.722 \mathrm{~g} / \mathrm{dL}$

Ressuscitation coefficient, $r=2.617 \mathrm{~g} / \mathrm{dL}$

Volume replacement, VR

Total blood volume, TBV

Blood Volume Formula from Nadler 1962:

$$
\begin{gathered}
\text { Female } B V=\text { height }(\mathrm{m})^{3} * 0.356+\text { weight }(\mathrm{kg}) * 0.033+0.183 \\
\text { Male } B V=\text { height }(\mathrm{m})^{3} * 0.367+\text { weight }(\mathrm{kg}) * 0.032+0.604
\end{gathered}
$$

\section{Sample Calculation}

$1.8 \mathrm{~m}$ tall, $70 \mathrm{~kg}$ male patient $1000 \mathrm{~mL}$ crystalloid resuscitation

Pre-op Hgb 15 g/dL, post-op Hgb 12.5 g/dL

Total Pre-Op Blood Volume $=4984 \mathrm{~mL}$

Estimated Blood Loss $=833 \mathrm{~mL}$

to preserve its integrity as critical primary data. It is well proven that categorization results in meaningful data waste, reduced statistical power, underestimation of betweengroup variance, and loss of ability to evaluate non-linear relationships. $^{40}$ Specifically, in prediction modelling, coarse categorization of predictors is strongly discouraged in the model development phase as valuable information is lost and the risk of overfitting is introduced. $^{41}$ Preservation of this data integrity allows each stakeholder (whether that be the treating clinician, the quality improvement lead, or the large database methodologist) to utilize the data in the manner that is most appropriate for their needs.

In this study, we note that visual estimation tended to provide lower blood loss volumes than formula-based or other techniques, a finding that was consistently found across most included studies. Nevertheless, given the sample sizes in most studies and lack of a priori power calculations in all included studies, any conclusions drawn would be at risk of type II error. ${ }^{42}$ Our findings are consistent with the existing literature describing visual estimation in the simulation setting, which allow for evaluation against a known blood quantity. Previous evaluations of visual techniques in a simulated operative environment show low precision or accuracy.,43 Healthcare practitioners frequently underestimate actual blood losses, a tendency that appears to be consistent across practitioner age, sex, and professional experience. $^{1,43,44}$ While there is some evidence of potential improvement in blood estimation accuracy following didactic teaching in a simulated environment, ${ }^{1,43}$ these findings have never been reproduced in a clinical setting.

Strong calls exist to improve the consistency and quality of surgical blood loss estimation, with some authors suggesting that blood loss is a neglected quality of care indicator that requires advancement of techniques for minimization in surgery. ${ }^{45}$ Nevertheless, as Stahl et al. note, the evaluation of any new blood loss estimation method in the operative setting is limited by the lack of a gold standard, and we must therefore make comparisons between potentially imperfect techniques. ${ }^{46}$ This is reflected in the common theme that we documented across estimation techniques and studies, where large SDs and CVs for EBL values were observed. This is partly influenced by significant differences between patients even within a similar cohort undergoing a similar surgery, a reality well known to practitioners. Nevertheless, the significant variability is likely also influenced by poor intrinsic reliability of the blood loss estimation techniques themselves. Interestingly, we found no consistent trend when comparing the $\mathrm{CV}$ across different techniques.

Despite the widespread use of EBL in clinical practice to guide perioperative blood management ${ }^{2}$ and as a quality of care or prognostic variable in the surgical literature, we have shown in this review that little standardization exists for its methodology. ${ }^{45}$ In addition, there is significant disagreement between techniques and these techniques are limited by significant case-to-case variation. While many perioperative risk models incorporate blood loss as an important predictor variable, their categorization as quantity-based cutoffs ${ }^{3-5}$ places a great deal of importance on the accuracy and reliability of blood loss 
measurement. In the era of evidence-based medicine, we cannot continue to ignore blood loss as a metric and must acknowledge the need for a fundamental change in the manner in which it is valued and assessed.

Based on our appraisal of the literature, we suggest formula-based techniques as the preferred standard methodology for estimating blood loss. The ideal blood loss formula should be simple to conduct, interpret, and reproduce. Robust formulae should incorporate patients' body habitus and fractional changes in hemoglobin or hematocrit, which account for the influence of hemodilution. A recent randomized-controlled trial by Ross et al. ${ }^{47}$ identifying expected changes in hemoglobin based on simultaneous controlled blood loss and crystalloid replacement in healthy blood donors offers considerable promise in this regard. The authors provide proof of hemodilution following blood loss and resuscitation, deriving a mathematical model based on Nadler's original work on blood volume estimates ${ }^{48}$ and using changes in hemoglobin to calculate blood loss. We provide a sample calculation in Fig. 2 for a $70 \mathrm{~kg}$ male patient with a $1,000-\mathrm{mL}$ crystalloid resuscitation and a hemoglobin drop from $15 \mathrm{~g} \cdot \mathrm{dL}^{-1}$ to $12.5 \mathrm{~g} \cdot \mathrm{dL}^{-1}$ for which an EBL of $833 \mathrm{~mL}$ is generated.

While it would be virtually impossible to assess accuracy against a true gold standard, the minimization of dependence of inter-observer reliability confers a potential advantage for formula-based techniques. In addition, the practical, reproducible, and non-resource intensive nature of the methodology would allow the surgical research community to speak a common language and interpret the EBL variable in the same manner worldwide. Nevertheless, given the substantial variation that was identified in our review even with formula-based techniques, optimization of this technique is still required.

This review has a number of strengths. It was performed using a comprehensive search with clear eligibility criteria, examines multiple blood estimation techniques, and adheres to modern best practice guidelines for the conduct of systematic reviews. ${ }^{14}$ Given the paucity of literature, we employed a pragmatic approach to data collection and presentation to emphasize clinical relevance.

This review has the following limitations, which should be considered when appraising and contextualizing these findings. Because of the expected paucity of literature, we sought to maximize inclusiveness and potential sample size by including a variety of blood loss estimation techniques, patient populations, surgical techniques, and surgical disciplines. As such, our findings are notably limited by significant clinical heterogeneity. While our pooled analyses provided point estimates that suggest visual estimation techniques provide lower EBL values than other techniques, these findings were not statistically significant. Importantly, our findings are limited by the modest sample sizes and lack of power calculations in the included studies, thus introducing potential type II errors. ${ }^{42}$ Nevertheless, as previously suggested by the Bradford Hill criteria, ${ }^{49}$ existence of a meaningful association is elucidated not only by strength but also by consistency among other factors, which we show across most studies included in this review. Our findings are also reliant on observational data, although it should be noted that the unique nature of blood loss evaluation allows for comparison within a single patient, thus eliminating the selection bias of intervention $v s$ control group differences. While the proposed standardization of blood loss estimation offers the potential to improve its utility at a population outcome level by reducing statistical noise, this may not necessarily translate to improved accuracy or increased prognostic significance. Specifically, the intended focus of this review is to summarize and advocate for improved methodology for blood loss estimation. Identifying meaningful clinical thresholds for subsequent action is not within the scope of this study. We acknowledge that a change in blood loss estimation methodology is unlikely to significantly alter short-term clinical decision-making for any one patient. Decisions to deviate from typical care pathways are often based on a more holistic evaluation of patient status, including hemodynamics and laboratory values because subtle differences in precision of blood loss estimation alone are less likely to be clinically relevant.

\section{Conclusion}

In summary, this systematic review and meta-analysis evaluated techniques for intraoperative blood loss estimation in major non-cardiac surgery. We found that visual techniques tended to provide lower EBL values than formula-based estimation or other techniques, though this effect was not statistically significant in pooled analyses, likely due to sample size limitations. We found significant case-by-case variation for all methods of blood loss evaluation and significant disagreement between techniques. Given the importance placed on EBL values, particularly for perioperative prognostication models, clinicians should consider the universal adoption of a practical and reproducible method for blood loss evaluation.

Author contributions Alexandre Tran and Guillaume Martel conceived the study idea, designed the study protocol, and completed the statistical analyses. Guillaume Martel and Jordan Heuser completed the literature search, literature screening, and data extraction. Alexandre Tran, Timothy Ramsay, Daniel I. McIsaac, and 
Jordan Heuser provided statistical and methodological expertise. All authors participated in the creation and revision of the manuscript.

\section{Disclosures None.}

Funding statement There were no funding sources or other support for this review.

Editorial responsibility This submission was handled by Dr. Philip M. Jones, Associate Editor, Canadian Journal of Anesthesia.

\section{References}

1. Dildy GA 3rd, Paine AR, George NC, Velasco C. Estimating blood loss: can teaching significantly improve visual estimation? Obstet Gynecol 2004; 104: 601-6.

2. American Society of Anesthesiologists Task Force on Perioperative Blood Management. Practice guidelines for perioperative blood management: an updated report by the American Society of Anesthesiologists Task Force on Perioperative Blood Management. Anesthesiology 2015; 122: 241-75.

3. Gawande AA, Kwaan MR, Regenbogen SE, Lipsitz SA, Zinner MJ. An Apgar score for surgery. J Am Coll Surg 2007; 204: 2018.

4. Callery MP, Pratt WB, Kent TS, Chaikof EL, Vollmer CM Jr. A prospectively validated clinical risk score accurately predicts pancreatic fistula after pancreatoduodenectomy. J Am Coll Surg 2013; 216: 1-14.

5. Prytherch DR, Whiteley MS, Higgins B, Weaver PC, Prout WG, Powell SJ. POSSUM and Portsmouth POSSUM for predicting mortality. Physiological and Operative Severity Score for the enUmeration of Mortality and morbidity. Br J Surg 1998; 85: 1217-20.

6. Morner ME, Gunnarsson $U$, Jestin $P$, Svanfeldt $M$. The importance of blood loss during colon cancer surgery for longterm survival: an epidemiological study based on a population based register. Ann Surg 2012; 255: 1126-8.

7. Katz SC, Shia J, Kiau KH, et al. Operative blood loss independently predicts recurrence and survival after resection of hepatocellular carcinoma. Ann Surg 2009; 249: 617-23.

8. McCullough JV, Roth JV, Ginbserg PC, Harkaway RC. Estimated blood loss underestimates calculated blood loss during radical retropubic prostatectomy. Urol Int 2004; 72: 13-6.

9. Yuzkat C, Soyalp C, Gulhas N. Comparison of the error rates of an anesthesiologist and surgeon in estimating perioperative blood loss in major orthopedic surgeries: a clinical observation study. JARSS 2019; 27: 291-7.

10. Bozickovic N, Popovic J, Kolak R, Popovic K, Popovic D. Application of one-compartmental bio-metric blood loss calculations with transfused blood volume taken into account after aneurysmectomy. Eur J Drug Metab Pharmacokinet 2011; 36: $103-8$

11. Brecher ME, Monk T, Goodnough LT. A standardized method for calculating blood loss. Transfusion 1997; 37: 1070-4.

12. Jaramillo $S$, Montane-Muntane $M$, Capitan D, et al. Agreement of surgical blood loss estimation methods. Transfusion 2019; 59: 508-15.

13. Lopez-Picado A, Albinarrate A, Barrachina B. Determination of perioperative blood loss: accuracy or approximation? Anesth Analg 2017; 125: 280-6.
14. Moher D, Liberati A, Tetzlaff J, Altman DG; PRISMA Group. Preferred reporting items for systematic reviews and metaanalyses: the PRISMA statement. Ann Intern Med 2009; 151: 264-9, W14.

15. Bland JM, Altman DG. Measuring agreement in method comparison studies. Stat Methods Med Res 1999; 8: 135-60.

16. Williamson PR, Lancaster GA, Craig TV, Smyth RL. Metaanalysis of method comparison studies. Stat Med 2002; 21: 201325.

17. Sanchez S, Godek S, Kent TS, Callery MP, Vollmer CM. Marked variance between estimated and calculated blood loss for pancreatic resection surgery. HPB 2011; 13 (Suppl. 1): 59 (abstract).

18. Slim K, Nini E, Forestier D, Kwiatkowski F, Panis Y, Chipponi J. Methodological index for non-randomized studies (minors): development and validation of a new instrument. ANZ J Surg 2003; 73: 712-6.

19. Beideian A, Mossholder $K W$. On the use of the coefficient of variation as a measure of divertsity. Org Res Methods 2000. https://doi.org/10.1177/109442810033005.

20. Friedrich JO, Adhikari NK, Beyene J. Ratio of means for analyzing continuous outcomes in meta-analysis performed as well as mean difference methods. J Clin Epidemiol 2011; 556: 64.

21. Baronofsky ID, Treoloar AE, Wangensteen $O H$. Blood loss in operations: a statistical comparison of losses as determined by the gravimetric and colorimetric methods. Surgery 1946; 20: 761-9.

22. Ghee L, Thomas S, Kowdley G, Patel S, Cunningham S. Measured vs estimated blood loss during pancreaticoduodenectomy and other major abdominal operations: interim analysis. HPB 2017; 19 (Suppl 1): S79 (abstract).

23. Guinn NR, Broomer BW, White W, Richardson W, Hill SE. Comparison of visually estimated blood loss with direct hemoglobin measurement in multilevel spine surgery. Transfusion 2013; 53: 2790-4.

24. Nelson NC, Ostby SA, Weaver AL, McGree ME, Gebhart JB, Bakkum-Gamez N. Estimated blood loss during vaginal hysterectomy and adnexal surgery described with an intraoperative pictographic tool. Female Pelvic Med Reconstr Surg 2018; 24: 347-51.

25. Oppenheim A, Pack GT, Abels JC, Rhoads CP. Estimation and significance of blood loss during gastro-intestinal surgery. Ann Surg 1944; 119: 865-72.

26. Uejima J, Moreland $N$, Penev S, McCarthy R, Carabini L. Estimation blood loss underestimates calculated blood loss in spinal fusion surgery. J Neurosurg Anesthesiol 2015; 27: 425 (abstract).

27. Brockner J, Ladegaard-Pedersen HJ, Engell HC, Donvig M. Blood-volume measurements before and after operation and determination of operative blood loss. Acta Anaesthesiol Scand 1969. https://doi.org/10.1111/j.1399-6576.1969.tb00953.x.

28. Budair B, Ahmede U, Hodson J, David M, Ashraf M, McBride T. Are we all guilty of under-estimating intra-operative blood loss during hip fracture surgery? J Orthop 2016; 14: 81-4.

29. Budny PG, Regan PJ, Roberts AH. The estimation of blood loss during burns surgery. Burns 1993; 19: 134-7.

30. Flordal PA, Ljungstrom $K G$, Edman B, Neander $G$. Effects of desmopressin on blood loss in hip arthroplasty. Controlled study in 50 patients. Acta Orthop Scand 1992; 63: 381-5.

31. Hurle R, Roma R, Maffezzini $M$, et al. A simple mathematical approach to calculate blood loss in radical prostatectomy. Urol Int 2004; 72: 135-9.

32. Orth VH, Rehm M, Thiel M, et al. First clinical implications of perioeprative red cell volume measurement with a nonradioactive marker (sodium fluorescein). Anesth Analg 1998; 87: 1234-8. 
33. Sehat KR, Evans $R$, Newman $J H$. How much blood loss is really lost in total knee arthroplasty? Correct blood loss management should take hidden loss into account. Knee 2000; 7: 151-5.

34. Solon JG, Egan C, McNamara DA. Safe surgery: how accurate are we at predicting intra-operative blood loss? J Eval Clin Pract 2013; 19: 100-5.

35. Delilkan AE. Comparison of subjective estimates by surgeons and anaesthetists of operative blood loss. Br Med J 1972; 2: 619-21.

36. Ram GG, Suresh $P$, Vijayaraghavan $P V$. Surgeons often underestimate the amount of blood loss in replacement surgeries. Chin J Traumatol 2014; 17: 225-8.

37. Wen L, Jin D, Xie W, et al. Hidden blood loss in posterior lumbar fusion surgery: an analysis of risk factors. Clin Spine Surg 2018; 31: 180-4.

38. Caceres E, Whittembury G. Evaluation of blood losses during surgical operations: comparison of the gravimetric method with the blood volume determination. Surgery 1959; 45: 681-7.

39. Adadevoh I, Udomesiet IC. Intraoperative blood loss evaluation on major orthopaedic surgery. Br J Anaesth 2012; 108 (S2): ii5564 (abstract).

40. Altman DG, Royston $P$. The cost of dichotomising continuous variables. BMJ 2006. https://doi.org/10.1136/bmj.332.7549.1080.

41. Steyerberg EW, Vergouwe $Y$. Towards better clinical prediction models: seven steps for development and an ABCD for validation. Eur Heart J 2014; 35: 1925-31.

42. Turner RM, Bird SM, Higgins JP. The impact of study size on meta-analyses: examination of underpowered studies in Cochrane reviews. PLoS One 2013. https://doi.org/10.1371/journal.pone. 0059202.

43. Meiser A, Casagranda O, Skipka G, Laubenthal H. Quantification of blood loss. How precise is visual estimation and what does its accuracy depend on? (German). Anaesthesist 2001; 50: 13-20.

44. Patton K, Funk DL, McErlean M, Bartfield JM. Accuracy of estimation of external blood loss by EMS personnel. J Trauma 2001; 50: 914-6.

45. Dixon E, Datta I, Sutherland FR, Vauthey JN. Blood loss in surgical oncology: neglected quality indicator? J Surg Oncol 2009; 99: 508-12.

46. Stahl DL, Groeben $H$, Kroepfl D, Gautam S, Eikermann M. Development and validation of a novel tool to estimate perioperative blood loss. Anaesthesia 2012; 67: 479-86.

47. Ross SW, Christmas AB, Fischer PE, et al. Defining dogma: quantifying crystalloid hemodilution in a prospective randomized control trial with blood donation as a model for hemorrhage. J Am Coll Surg 2018; 227: 321-31.

48. Nadler SB, Hidalgo JH, Bloch T. Prediction of blood volume in normal human adults. Surgery 1962; 51: 224-32.

49. Howick J, Glasziou P, Aronson JK. The evolution of evidence hierarchies: what can Bradford Hill's 'guidelines for causation' contribute? J R Soc Med 2009; 102: 186-94.

Publisher's Note Springer Nature remains neutral with regard to jurisdictional claims in published maps and institutional affiliations. 